\title{
Histórias de vida: uma produção de textos funcionais
}

\author{
Maria Goreth de Sousa Varão \\ UFPI
}

\begin{abstract}
Resumo
O projeto de extensão Produção de Textos: histórias de vida, realizado em 2007, pretendia sair do enfoque tradicional do ensino de redação e praticar as novas tendências sobre leitura e produção textual, com a finalidade de fazer com que os alunos da disciplina Português I- Práticas de Redação, do Curso de Letras, deixassem de produzir textos hipotéticos para produzirem textos funcionais. $\mathrm{O}$ projeto resultou na produção de um livro publicado pela Universidade Federal do Piauí. Espero que esta proposta abra novos caminhos para o ensino/aprendizagem, na graduação, partindo de teorias sobre os gêneros e tipologias textuais.

Palavras-Chave: graduação, gêneros textuais, pesquisa, produção de textos
\end{abstract}

\begin{abstract}
:
The extension project Text Production: stories of life, conducted in 2007, had the double objective of abandoning the traditional approach to the teaching of writing and also of practicing new trends in reading and text production. The particular aim of the project was to make students that were taking the subject of Portuguese I-Writing Practice, in the Letters Course, produce functional, instead of hypothetical, texts. The result of the project was a book published by the Federal University of Piauí. Hopefully, this proposal will open new ways of teaching/learning, in undergraduate courses, starting from theory of genres and text types.
\end{abstract}

Keywords: undergraduate writing, genres, research, text production

\section{INTRODUÇÃO}

Como seres sociais que somos, estamos o tempo todo praticando a comunicação, ou seja, contando algo, ouvindo um relato de alguém, pedindo informação, etc. Nesses momentos, trabalhamos com textos funcionais dos mais variados gêneros.

Segundo Koch (2004), os Parâmetros Curriculares Nacionais de Língua Portuguesa (PCNs) preconizam que no ensino de leitura e produção de textos o professor trabalhe com a maior variedade possível de gêneros, em particular, aqueles aos quais os discentes se encontram expostos no seu dia-a-dia e que eles necessitam dominar para ampliar a sua competência de atuação social. 
Koch e Elias (2006) dizem que não é possível determinar a quantidade desses gêneros, pois, como práticas sociocomunicativas, eles são dinâmicos e podem mudar em sua constituição, o que resultaria em novos gêneros. Entretanto, temos condições de reconhecer os gêneros, produzi-los e/ou compreendê-los, porque desenvolvemos uma competência metagenérica, ou seja, com a prática de leitura e de produção de textos variados, desenvolvemos a capacidade de identificar os diferentes tipos e gêneros textuais, quando necessário, pela sua funcionalidade.

Concordo com as autoras e considero que uma forma de desenvolver essa competência textual é ser um sujeito ativo no processo do aprendizado, ou seja, desenvolver um trabalho que envolva a academia, para que os alunos tenham contato com as teorias sobre leitura, tipos e gêneros textuais, e produção de textos, de autores como Koch (2003, 2004), Koch e Elias (2006), Garcez (2001), entre outros; e a sociedade, para os alunos produzirem textos com uma funcionalidade real. Dessa forma, os discentes perceberão que seus textos serão lidos e criticados por seus pares, o que pode suscitar mudanças na forma de trabalhar a Produção de Texto na academia.

Com base nesses termos e percebendo a falta de motivação dos discentes na disciplina Português I, pensei e elaborei o Projeto Produção de Textos: histórias de vida como atividade prática da disciplina, visando a uma produção de textos funcionais.

\section{DA ESTRUTURA DO PROJETO}

Os estudiosos das correntes contemporâneas, que trabalham com a leitura e a produção de texto, comungam a idéia de que a redação escolar precisa ser trabalhada, considerando a funcionalidade dos textos, o que leva o alunado a uma proximidade com as práticas sociais vigentes.

Considerando essa tendência para a produção do texto funcional, resolvi mudar a metodologia e dinamizar a disciplina, possibilitando o contato direto do aluno com a pesquisa de campo, para que ele vivenciasse o processo da pesquisa: conhecer o contexto social da pesquisa e os informantes; saber como agir no meio, coletar os dados em entrevista oral e gravá-los; transcrever dados; fazer o registro com fotos; e lapidar a informação, transformando-a em um dos gêneros textuais escolhidos previamente.

O projeto Produção de Textos: histórias de vida foi audacioso e desafiante pois tinha como proposta levar os alunos a praticarem, junto à comunidade, o aprendizado da academia. A meta era coletar dados sobre a história e a cultura da cidade de Picos-PI, a 
partir do relato de membros da sociedade picoense, informantes da pesquisa, e transformá-los em gêneros textuais variados, para publicar em um livro. Isso foi pensado com o objetivo de sair do enfoque tradicional do ensino de Redação e praticar as novas tendências em ensino de Leitura e Produção de Textos, além de viabilizar a prática da pesquisa de campo aos alunos da disciplina Português I - Prática de Redação, do Curso de Licenciatura Plena em Letras, da UFPI - Campus Universitário de Picos.

O projeto em si não tinha pretensões científicas em relação ao estudo da história e da cultura da sociedade picoense; ele buscava, a princípio, fazer com que os alunos produzissem textos funcionais que seriam publicados em uma coletânea e, com isso, abrir novos caminhos para o ensino/aprendizagem. Também procurava desenvolver uma prática interdisciplinar na academia para corroborar a idéia do aprendizado coletivo. Uma terceira pretensão foi fazer os alunos entenderem a importância do conhecimento histórico, social e cultural de uma sociedade para a formação do cidadão.

Desta feita, ressaltamos que as informações contidas nos textos são provenientes do relato oral de alguns moradores da cidade de Picos (PI), selecionados considerando os seguintes aspectos: a origem (são picoenses), eles continuam morando na cidade, a idade (mínima de 60 anos) e fazem parte de famílias tradicionais que participaram da criação da cidade. Nessas condições, as informações usadas nos textos da coletânea, ficam sujeitas à comprovação, ou não, em relatos futuros, feitos por pesquisas científicas realizadas com maior rigor técnico.

\section{PROCEDIMENTOS METODOLÓGICOS}

O projeto foi concebido e implantado pela professora da disciplina Português I Práticas de Redação, como atividade de extensão, e teve a duração de 06 (seis) meses, com início em março e término em setembro de 2007. A professora assumiu a coordenação geral do projeto que contou com a colaboração dos alunos, pesquisadores e produtores dos textos do livro, uma monitora da disciplina e quatro professores de disciplinas distintas (que atuaram ativamente junto às equipes de pesquisa e na correção dos textos produzidos pelos alunos).

As etapas centradas no ensino (conhecimento do referencial teórico); planejamento das atividades e seleção e/ou preparação de material foram realizadas na sala de aula, no horário da disciplina, no Campus Universitário de Picos. Já as atividades de pesquisa e coleta de dados foram realizadas fora de sala, via material 
bibliográfico e junto à comunidade picoense, com os informantes da pesquisa. A coleta, junto à comunidade, foi feita por meio de entrevista (gravada) com o representante de cada uma das famílias escolhidas e por fotos representativas de familiares e/ou eventos.

A coordenadora do projeto apresentou a proposta de trabalhos aos discentes, explicou como seria realizada cada etapa e destacou a contribuição que a atividade traria para o ensino-aprendizagem dos conteúdos da disciplina Português I - Práticas de Redação, além da obrigatoriedade e seriedade que deveriam assumir na realização do projeto. Ela também viabilizou o acesso dos discentes às teorias que serviram de base para a realização do trabalho.

Na primeira etapa do Projeto, os alunos conheceram as teorias existentes sobre leitura, tipos e gêneros textuais, além das formas de texto que iriam produzir com os dados coletados na pesquisa de campo, como: relato histórico, reportagem, receita culinária, texto de instrução, conto, artigo de opinião e outros. Foi dedicado um tempo maior ao gênero entrevista, para que os alunos-pesquisadores conhecessem as especificidades do gênero: estrutura, as informações que devem constar no corpo do texto, as diferenças entre a entrevista oral e a escrita, como proceder durante a coleta dos dados, como gravar os depoimentos, etc. Por fim, foi elaborado um roteiro de entrevista, que foi usado na coleta de dados.

$\mathrm{Na}$ segunda etapa, a professora da disciplina fez um levantamento das famílias tradicionais da cidade, possíveis candidatas a serem entrevistadas. Depois, juntos com os outros professores e a monitora, escolheu 06 delas para serem as informantes da pesquisa. Na sequência, alunos foram organizados em 06 equipes, sendo que cada uma ficou encarregada de uma família específica para realizar a coleta de dados.

$\mathrm{Na}$ terceira etapa, realizou-se um contato com o representante das famílias escolhidas, com a finalidade de apresentar o projeto e conseguir a autorização para coletar os dados e divulgar os resultados no livro.

$\mathrm{Na}$ quarta etapa, os dados foram coletados por meio de entrevistas e fotos. Depois as entrevistas foram transcritas e os dados foram usados na produção dos gêneros textuais selecionados previamente pelo grupo.

A última etapa do projeto ficou a cargo da Universidade Federal do Piauí UFPI: a impressão do livro, produzido como resultado desse projeto, e dos certificados dos participantes.

Os professores envolvidos na atividade e a monitora ficaram encarregados de realizar as reuniões com as equipes de pesquisa para ajudar na realização dos trabalhos; 
avaliar o cumprimento das etapas e a coleta dos dados; além de orientar na produção do texto final. A coordenadora também se reunia periodicamente, na sala de aula, com as equipes de pesquisadores para verificar a assiduidade dos mesmos, bem como o cumprimento, no prazo estabelecido, das etapas do projeto correspondentes a cada equipe. Nesse processo, os alunos foram avaliados individualmente e em equipe pela sua atuação diante da realização das atividades.

No término dos trabalhos, foi feito um relatório para a universidade sobre o desenvolvimento do projeto, enfatizando o resultado positivo para o ensino aprendizagem da produção textual dos alunos participantes.

\section{O LIVRO}

Levando em conta a diversidade de textos produzidos pelos alunos, a coletânea foi organizada em um livro denominado Picos: histórias que as famílias contam, composto de 06 (seis) capítulos, em que cada um aborda um gênero específico e, apesar da diversidade de gêneros, todos os textos fazem parte do resgate da história cultural de Picos: relatando histórias de vida, descrevendo e orientando como se procediam as brincadeiras infanto-juvenis, contando como se preparavam as comidas e bebidas em décadas passadas, informando sobre o modo de vida da sociedade picoense ao longo das décadas e/ou opinando sobre as mudanças ocorridas nesta sociedade.

$\mathrm{Na}$ sequência, apresento dois dos textos produzidos pelos alunos, como exemplo:

\section{Gênero reportagem:}

\section{PROMESSA, DEVOÇÃO E FÉ - NOSSA SENHORA DOS REMÉDIOS - A PADROEIRA DE PICOS.}

Entre 1838 a 1841, período que aconteceu a guerra da Balaiada, tendo o Maranhão como cenário, as tropas de Picos foram enviadas para essa batalha sob o comando do Capitão José Francisco Fontes. Entre eles, estavam os filhos do vaqueiro João das Dores e o do Coronel Victor de Barros Silva. A história revela que o vaqueiro que trabalhava na fazenda do Coronel Victor, fez uma promessa a Nossa Senhora, para que os jovens voltassem vivos da guerra.

Como a promessa do vaqueiro foi atendida e os rapazes retornaram a suas famílias, o coronel encomendou, de Portugal, uma imagem de nossa Senhora dos Remédios, no valor de 
$\$ 40.000,00$ (quarenta mil réis), o equivalente ao preço de dez vacas paridas, o que, na época, era considerada uma verdadeira fortuna.

Ao ser comunicado de que a imagem havia chegado a Salvador, na Bahia, o Coronel designou um dos seus escravos para ir buscar a Santa e trazê-la a pé até Picos. O escravo e a imagem chegaram à cidade no dia 31 de dezembro de 1847, o que valeu ao escravo a concessão da carta de alforria pó este ter cumprindo essa importante missão.

A imagem foi abençoada, em janeiro do ano seguinte, pelo Padre cearense Francisco de Paula Moura, que foi o primeiro sacerdote do povoado de Picos. Assim, Nossa Senhora dos Remédios passou a ser a santa de devoção da população. Nesta época, Picos era apenas um povoado e foi escolhido em 1851 para ser sede da freguesia de Nossa Senhora dos Remédios que, somente em 1855, passaria à condição de Vila.

Mesmo sendo grande a devoção a Nossa Senhora dos Remédios, a capela em sua homenagem só foi construída em 1871, pelo Padre José Antonio Maria Pereira Ibiapina, venerado apóstolo dos sertões nordestinos. Essa construção, iniciada há bastante tempo, 1848, segundo outra informante, foi efetivada em 90 dias e a imagem de Nossa Senhora foi conduzida da capela de São José para o novo templo, acompanhada de uma grande multidão.

Os sinos da igreja foram doados no mesmo ano pelo fazendeiro Justiniano Antonio de Macedo. Para muitos moradores, o desenvolvimento de Picos em todos os setores se deu graças à invocação a Nossa Senhora dos Remédios e da fé de sua população, às graças recebidas ao longo da história de construção da cidade.

\section{Gênero conto:}

\section{TUDO É POSSÍVEL PELO AMOR}

Na década de sessenta, na cidade de Picos, a Praça Félix Pachêco era bem movimentada por pessoas de todas as idades e, principalmente pelos jovens que freqüentavam constantemente.

Um dia de muito movimento, em razão dos festejos da padroeira da cidade, após a missa, Eva, uma jovem simples, alegre e simpática foi até a referida praça, em companhia de algumas amigas. Chegando, encontra Adão, rapaz extrovertido e bem carismático.

Naquele clima festivo, de muita alegria e descontração os dois começaram a namorar, mesmo sabendo que suas famílias eram rivais continuaram o namoro escondido.

Mas depois de um tempo, Adão tomou coragem e, quebrando as regras de sua família, resolveu então, falar com os pais da moça e pedir sua mão em casamento. 
A resposta dos mesmos não poderia ser outra a não ser um "não!". Então o rapaz resolveu seguir em frente com seu propósito. Como ele tinha amizade com uma das serviçais da família, então enviou uma carta à Eva, informando uma forma de fugirem e se casarem posteriormente.

Aquela rua que Eva morava era pouco iluminada, então, facilitou a sua fuga, onde altas horas da noite com a ajuda de um amigo, Adão conseguiu raptar Eva disfarçada com vestimentas de homem.

Somente assim eles conseguiram viver todo aquele amor proibido durante dez anos. Dessa união nasceram nove filhos, depois desse tempo, Adão morreu vítima de afogamento em uma enchente que devastou parte da cidade de Picos, deixando sua esposa viúva muito cedo, mas esta nunca substituiu seu amor por outro.

Vale enfatizar que as informações divulgadas nos textos têm origem nas histórias orais dos representantes de famílias picoenses, informantes dessa pesquisa, e foram produzidos na linguagem dos alunos-pesquisadores.

\section{PALAVRAS FINAIS}

O projeto foi positivo e aproximou os discentes da sociedade, fazendo com que muitos deles conhecessem sua cultura e valores, que estão se perdendo com a modernidade. O que, no início, era rejeição para alguns alunos, tornou-se algo motivador e interessante e, assim, passaram a dedicar o tempo livre para realizar as atividades de maneira que o trabalho fosse concluído. O livro foi publicado, e a noite de autógrafos concretizou-se como algo muito importante para esses alunos, que se tornaram autores de um livro, e para os representantes das famílias entrevistadas, que vieram à universidade em uma noite festiva participar dessa comemoração.

Como a UFPI tem por finalidade o ensino, a pesquisa e a extensão, e é estruturada para formar profissionais que atuarão na sociedade, é imperioso registrar que a realização do Projeto Produção de Textos: histórias de vida, e a publicação dessa coletânea, teve um significado ímpar, já que propiciaram aos discentes da disciplina Português I- Prática de Redação iniciarem a trajetória no Curso de Letras atuando no ensino e na pesquisa, além de aprenderem a trabalhar em equipe, coletar dados, analisar e registrar as informações coletadas. Isso contribuiu para que os mesmos percebessem a importância da interação universidade e sociedade na produção do conhecimento. 
Este trabalho tem sua importância por proporcionar aos alunos a realização de uma atividade prática, que extrapolou os limites da exposição teórica acerca dos gêneros textuais, e, também, pelo encontro entre as gerações: a geração anterior (os entrevistados) e a geração nova (os pesquisadores), levando esta a beber no poço de conhecimento e de experiência de vida daquela, além de conhecer a memória de um povo: sua história, sua cultura e seus costumes.

Por outro lado, a coletânea, resultado da produção dos textos dos alunos, é uma demonstração viva de que a tão sonhada "transversalidade no ensino" é perfeitamente possível, desde que os professores e os alunos associem teoria e prática, buscando o conhecimento dentro e fora da instituição de ensino. Esta afirmação só faz sentido porque durante a fase de desenvolvimento deste trabalho os alunos conseguiram adquirir conhecimentos não só na área de Produção de Texto, nosso objetivo primeiro, mas também nas áreas de História, Sociologia e Cultura Geral, além das belas experiências de vida com as quais tiveram contato, tendo em vista o envolvimento e a participação de professores das referidas áreas e de pessoas da comunidade picoense.

\section{REFERÊNCIAS}

Freire, P. (2000). Política e educação: ensaios. São Paulo: Cortez.

Garcez, L. H. C. (2001). Técnicas de Redação: o que é preciso saber para escrever bem. São Paulo: Martins Fontes (Ferramentas).

Koch, I. V. (2003). Desvendando os segredos do texto. 2 ed. São Paulo: Cortez. . (2004). Introdução à Lingüística Textual: trajetória e grandes temas. São Paulo: Martins Fontes.

Koch, I. V. \& Elias, V. M. (2006). Ler e Compreender: os sentidos do texto. São Paulo: Contexto.

Pécora, A. (2004). Problemas de Redação. SP: Martins Fontes.

Prado Junior, C. (1999). Formação do Brasil contemporâneo. São Paulo: Brasiliense.

Rodrigues, A. de J. (2006). Metodologia Científica. São Paulo: Avecamp.

Varão, M. G. S. (org.) (2007). Picos: histórias que as famílias contam. Teresina-PI: EDUFPI.

\section{A AUTORA}


Maria Goreth de Sousa Varão é professora titular da UFPI- Universidade Federal do Piauí-Campus de Picos. Compõe o corpo docente do curso de graduação em Letras. Sua área de pesquisa envolve linguística textual, práticas de leitura e produção de texto, letramento virtual.

E-mail: gorethvarao@gmail.com.br 